University of Nebraska - Lincoln

DigitalCommons@University of Nebraska - Lincoln

2000

\title{
Hyperphosphorylation of the Asialoglycoprotein Receptor in Isolated Rat Hepatocytes Following Ethanol Administration
}

\author{
Benita L. McVicker \\ University of Nebraska Medical Center, Omaha, Nebraska \\ Dean J. Tuma \\ University of Nebraska Medical Center, Omaha, Nebraska \\ Carol A. Casey \\ University of Nebraska Medical Center, ccasey@unmc.edu
}

Follow this and additional works at: https://digitalcommons.unl.edu/publichealthresources

Part of the Public Health Commons

McVicker, Benita L.; Tuma, Dean J.; and Casey, Carol A., "Hyperphosphorylation of the Asialoglycoprotein Receptor in Isolated Rat Hepatocytes Following Ethanol Administration" (2000). Public Health Resources. 9 .

https://digitalcommons.unl.edu/publichealthresources/9

This Article is brought to you for free and open access by the Public Health Resources at DigitalCommons@University of Nebraska - Lincoln. It has been accepted for inclusion in Public Health Resources by an authorized administrator of DigitalCommons@University of Nebraska - Lincoln. 


\title{
Hyperphosphorylation of the Asialoglycoprotein Receptor in Isolated Rat Hepatocytes Following Ethanol Administration
}

\author{
Benita L. McVicker, Dean J. Tuma and Carol A. Casey* \\ Liver Study Unit, Department of Veterans Affairs Medical Center, Omaha, NE 68105; And \\ Departments of Internal Medicine and Biochemistry \& Molecular Biology, University of Nebraska \\ Medical Center, Omaha, NE 68198, U.S.A.
}

\begin{abstract}
Ethanol administration leads to altered function and impaired receptor-mediated endocytosis of the hepatocyte asialoglycoprotein receptor (ASGP-R). The purpose of the present study was to examine the effects of ethanol on the phosphorylation of the ASGP-R to determine whether this post-translational modification could contribute mechanistically to the observed ethanol-induced alterations. The methodological approach of this work involved the measurement of the phosphorylation state of the receptor obtained from isolated rat hepatocytes, using a combination of experimental designs from the biosynthetic incorporation of phosphate to the determination of steady-state phosphotyrosine levels. We report here that both short-term (1to 2-week) and chronic (5-to 7-week) periods of ethanol administration resulted in a significant increase in the steady-state phosphotyrosine protein in the ASGP-R. In addition, in vitro incorporation of $\left[\gamma-{ }^{32} \mathrm{P}\right] \mathrm{ATP}$ using a permeabilized cell assay system similarly showed an increase in tyrosine-phosphorylated receptors. Furthermore, metabolic radiolabeling of hepatocytes with $\left[{ }^{32} \mathrm{P}\right]$ orthophosphate demonstrated hyperphosphorylation of the ASGP-R in cells obtained from chronically ethanol-fed animals. Finally, our results revealed that dephosphorylation of the ASGP-R was unaffected by ethanol administration, indicating that kinase activity rather than impaired phosphatase action contributes to the increased phosphorylation state of the receptor. Overall, the results presented in this study demonstrated that the extent of tyrosine phosphorylation of the receptor is significantly higher in hepatocytes obtained from ethanol-fed animals. We conclude that hyperphosphorylation of the ASGP-R may be a contributing factor to the impaired function of the receptor elicited by ethanol administration. BIOCHEM PHARMACOL 60;3:343-351, 2000.
\end{abstract}

KEY WORDS. endocytosis; phosphorylation; protein trafficking; inactivation; post-translational modification; ethanol-induced alterations

It has been established previously that ethanol administration results in altered protein trafficking in hepatocytes [1]. Studies have demonstrated that ethanol treatment induces impairments in glycoprotein secretion and in the assembly of newly synthesized proteins into the plasma membrane $[1$, 2]. In subsequent work from our laboratory, we have shown that chronic ethanol administration also impairs the cellular protein trafficking process of RME $\dagger$ markedly [3].

The RME process provides the cell with an intracellular pathway along which extracellular proteins are internalized via clathrin-coated vesicles and transported to targeted locations within the cell [4]. Using a hepatocyte-specific receptor, the ASGP-R, and the ligand ASOR as the model

\footnotetext{
* Corresponding author: Dr. Carol A. Casey, Liver Study Unit, Department of Veterans Affairs Medical Center, 4101 Woolworth Avenue, Omaha, NE 68105. Tel. (402) 346-8800 (Ext. 3737); FAX (402) 449. 0604; E-mail: ccasey@unmc.edu

$\dagger$ Abbreviations: RME, receptor-mediated endocytosis; ASGP-R, asialoglycoprotein receptor; ASOR, asialoorosomucoid; RHL-1, rat hepatic lectin; PMSF, phenylmethylsulfonyl fluoride; and MEM, modified Eagle's medium.

Received 13 December 1999; accepted 1 February 2000.
}

system, work from our laboratory has shown that RME is susceptible to impairment by ethanol treatment. Results from those studies indicated that in addition to lowered receptor number and altered receptor recycling, there were decreases in the internalization and degradation of the ligand ASOR as well as defects in the dissociation of the ASGP-R/ASOR complex in the endosomes [3, 5, 6]. More recently, studies have revealed that the function of the ASGP-R is altered differentially after exposure to alcohol over a time course of administration [7]. It has been found that after short-term alcohol feeding of 1-2 weeks, the ASGP-R is inactivated as well as redistributed in the cell, ultimately resulting in an intracellular accumulation of the ASGP-R in hepatocytes from ethanol-fed animals. After longer, more chronic periods of alcohol feeding, an actual decrease in receptor protein content was observed as a result of a reduction in ASGP-R transcript levels and receptor synthesis.

In the present study, we examined a potential mechanism that could be involved in these ethanol-induced impairments, that of the phosphorylation state of the 
receptor. It has been shown previously that protein phosphorylation can play a significant role in the regulation of endocytic receptors, including the ASGP-R. Alterations in RME of the ASGP-R have been demonstrated following treatment with protein phosphatase [8] as well as protein kinase inhibitors $[9,10]$. In addition, the regulation of RME by reversible protein phosphorylation was found to occur at several steps along the endocytic pathway. For example, the sequestration of ASGP receptors at the plasma membrane in early internalization events has been shown to be regulated by a cellular tyrosine kinase [11], which was found to be associated with the receptor [11]. Phosphorylation of the ASGP-R has also been implicated in the regulation of post-internalization endocytic events because the transient phosphorylation of intracellular receptors was shown to be a necessary event that precedes the inactivation and subsequent uncoupling of receptor/ligand complexes [12]. Furthermore, a correlation between the phosphorylation and dephosphorylation of receptor protein residues and recycling events has been supported through the identification of a pool of phosphorylated ASGP receptors that do not recycle back to the cell surface as normal [13]. Thus, the phosphorylation state of the ASGP-R may provide a signal or conformational adjustment for the receptor to proceed properly within the RME cycle. The ASGP-R is distributed randomly along the sinusoidal and lateral plasma membrane and consists of three polypeptide subunits identified in the rat by SDS-PAGE at 42, 49, and $54 \mathrm{kDa}$. The three rat hepatic lectin subunits contain serine and threonine residues that are potential phosphorylation sites; however, only the major subunit RHL-1 contains a cytoplasmic tyrosine [14]. It is the phosphorylation of this single tyrosine residue of the receptor that has been implicated in the regulation of ASGP-R function and endocytosis. Therefore, the purpose of this study was to examine the relationship of tyrosine phosphorylation of the ASGP-R and the function of the receptor in rat hepatocytes by investigating the effects of ethanol on this post-translational modification. In these studies, we used isolated cells from animals fed ethanol for 1-2 weeks and 5-7 weeks, the periods in which we observed the differential effects of ethanol on ASGP-R function, to examine the phosphorylation state of the receptor. We determined the steady-state level of phosphotyrosine protein present in the ASGP-R, the metabolic incorporation of orthophosphate into the receptor, and the level of in vitro tyrosine-phosphorylated ASGP-R through $\left[\gamma^{32}\right.$ P]ATP labeling.

\section{MATERIALS AND METHODS Ethanol Administration and Hepatocyte Preparation}

Male Wistar rats weighing 140-160 g were purchased from Charles River Laboratories. Initially, the animals were fed a Purina chow diet and allowed to acclimate to their surroundings for a period of 3 days. Then the rats were paired according to weight and fed either control or ethanol (36\% of calories) Lieber-DeCarli diet [15] for periods of $1-2$ or
5-7 weeks. The diet was purchased from Dyets, Inc. This project was approved by the Animal Studies Subcommittee of the Omaha Department of Veterans Affairs Medical Center. The animals were handled in accordance with applicable local and federal regulations concerning laboratory animals. Hepatocytes were obtained from the livers of control and ethanol-fed rats by a modified collagenase perfusion technique previously described by our laboratory [3]. The isolated cells were washed with Krebs-Ringer buffer, purified over a 35\% Percoll gradient, and equilibrated at $37^{\circ}$ for 45 min in Eagle's buffer containing 0.1\% BSA. Then the hepatocytes were washed, counted, resuspended in Eagle's/BSA medium, and placed on ice until they were divided for the various experiments.

\section{Western Blot Analysis}

ASGP-R was isolated from control and ethanol-treated animals by immunoprecipitation with anti-ASGP-R antibody followed by capture on Protein A-Sepharose as previously described [7]. For phosphotyrosine detection, the immunoprecipitated ASGP-R protein resolved on 10\% SDS-PAGE was transferred to nitrocellulose with the addition of $100 \mu \mathrm{M}$ sodium orthovanadate in the transfer buffer. After the protein transfer, the blots were incubated for $20 \mathrm{~min}$ at $37^{\circ}$ in blocking buffer [0.01 M Tris ( $\left.\mathrm{pH} 7.5\right)$, $0.1 \mathrm{M} \mathrm{NaCl}, 0.1 \%$ Tween 20, and 1\% BSA], followed by incubation for $60 \mathrm{~min}$ at $37^{\circ}$ with a 1:2000 dilution of horseradish peroxidase-conjugated anti-phosphotyrosine monoclonal antibody, PY20 (Transduction Laboratories), in blocking buffer. Next the blots were washed for $60 \mathrm{~min}$ with several changes of buffer [0.01 M Tris (pH 7.5), 0.1 M $\mathrm{NaCl}, 0.1 \%$ Tween 20], incubated with chemiluminescent detection reagents (ECL reagents, Amersham), and exposed to x-ray film for 30-60 sec. After the phosphotyrosine antibody analysis, the blots were stripped in $0.2 \mathrm{M}$ $\mathrm{NaOH}$, washed with $\mathrm{H}_{2} \mathrm{O}$, and blocked as before. The blots then were incubated with buffer containing $0.15 \mathrm{M} \mathrm{NaCl}$, $50 \mathrm{mM}$ Tris $-\mathrm{HCl}, 3.5 \% \mathrm{BSA}$, and the serum against ASGP-R (1:200) for $1 \mathrm{hr}$ at room temperature. After washing in $1 \%$ Tween $20,50 \mathrm{mM}$ Tris- $\mathrm{HCl}$ buffer, the blots were incubated with $1.0 \times 10^{5} \mathrm{cpm} / \mathrm{mL}$ of ${ }^{125} \mathrm{I}$-labeled Protein A for $1 \mathrm{hr}$, and washed for a final time with the Tween-Tris- $\mathrm{HCl}$ buffer, followed by quantification of the ASGP-R protein content present through PhosphorImager analysis.

\section{In Vitro ASGP-R Phosphorylation in Permeabilized Rat Hepatocytes}

Isolated hepatocytes from the control and ethanol-treated animals were radiolabeled according to the procedure of Haynes et al. [12] with slight modifications. After incubation in cytosol buffer [ $10 \mathrm{mM} \mathrm{NaCl}, 140 \mathrm{mM} \mathrm{KCl}, 2 \mathrm{mM}$ $\mathrm{MgCl}_{2}, 2 \mu \mathrm{M} \mathrm{CaCl}_{2}, 10 \mathrm{mM}$ HEPES, (pH 7.4)] for $20 \mathrm{~min}$ at $4^{\circ}$ with $0.006 \%$ digitonin, the cells were centrifuged at $350 \mathrm{~g}$, washed with digitonin-free cytosol buffer three times, 
and resuspended at $10-20 \times 10^{6}$ cells $/ \mathrm{mL}$ in phosphorylation buffer (cytosol buffer $+5 \mathrm{mM} \mathrm{MnCl}_{2}, 140 \mu \mathrm{M}$ PMSF, $3 \mathrm{mM} \mathrm{Na}_{3} \mathrm{VO}_{4}$, and $10 \mathrm{mM} \mathrm{NaH}_{2} \mathrm{PO}_{4}$ ). [ $\left.\gamma-{ }_{-}{ }^{32} \mathrm{P}\right]$ ATP (3000 $\mathrm{Ci} / \mathrm{mmol}$ ) purchased from NEN Life Science Products was added to the cells at $500 \mu \mathrm{Ci} / \mathrm{mL}$ and incubated at $4^{\circ}$ for the appropriate time period, and the reaction was terminated by the addition of 1 vol. stop buffer $[142 \mathrm{mM} \mathrm{NaCl}$, $6.7 \mathrm{mM} \mathrm{KCl}, 10 \mathrm{mM}$ HEPES (pH 7.4), 20 mM EDTA, 3 $\mathrm{mM} \mathrm{Na}_{3} \mathrm{VO}_{4}, 10 \mathrm{mM} \mathrm{NaH}_{2} \mathrm{PO}_{4}$, and $140 \mu \mathrm{M}$ PMSF]. The cells were centrifuged $(350 \mathrm{~g})$ and washed three additional times with stop buffer, after which the cell pellet was resuspended in extraction buffer [142 $\mathrm{mM} \mathrm{NaCl}, 6.7 \mathrm{mM}$ $\mathrm{KCl}, 10 \mathrm{mM}$ HEPES ( $\mathrm{pH}$ 7.4), $133 \mu \mathrm{M}$ PMSF, $3 \mathrm{mM}$ $\mathrm{Na}_{3} \mathrm{VO}_{4}, 10 \mathrm{mM} \mathrm{NaH}{ }_{2} \mathrm{PO}_{4}, 10 \mathrm{mM} \mathrm{CaCl}$, and $1.5 \%$ Triton $\mathrm{X}-100$ ] and incubated with end-over-end rotation for $2 \mathrm{hr}$ at $4^{\circ}$. After solubilization with the Triton detergent, the mixture was centrifuged at $10,000 \mathrm{~g}$ for $20 \mathrm{~min}$ at $4^{\circ}$, and the ASGP-R protein was purified from the supernatant by incubation with anti-ASGP-R antibody followed by Protein A-Sepharose (Pharmacia). The ASGP-R samples were resolved on 10\% SDS-PAGE and transferred to nitrocellulose as described in the western blot procedure, and the recovered radioactivity was quantified by PhosphorImager and autoradiographic analysis.

In vitro dephosphorylation of the radiolabeled ASGP-R protein was performed by placing the permeabilized cells in a $37^{\circ}$ incubator for $0,10,20$, and $60 \mathrm{~min}$, or as indicated. The reaction was terminated with the addition of $0.5 \mathrm{~mL}$ stop buffer followed by washing and extraction of the ASGP-R as previously mentioned. The recovery of ${ }^{32} \mathrm{P}$ labeled ASGP-R in the dephosphorylation experiments by immunoprecipitation was performed as just described for the in vitro phosphate analysis.

\section{Metabolic Labeling of the Receptor}

Isolated cells obtained from control and ethanol-fed animals were seeded at $2.0 \times 10^{6}$ cells $/ 35-\mathrm{mm}$ plate in phosphate-free MEM (Sigma, Cat. No. M 3786)/5\% fetal bovine serum containing $1 \mathrm{nmol} / \mathrm{L}$ of insulin and $10 \mathrm{nmol} / \mathrm{L}$ each of streptomycin and penicillin. The cells were incubated at $37^{\circ}$ for $1-2 \mathrm{hr}$, washed once, and incubated with fresh phosphate-free MEM containing 5\% dialyzed serum for an additional $3 \mathrm{hr}$ at $37^{\circ}$ prior to the addition of $\left.{ }^{32} \mathrm{P}\right]$ orthophosphate (Amersham, PBS41) to a final concentration of $1.0 \mathrm{mCi} / \mathrm{mL}$. Following overnight radiolabeling at $37^{\circ}$, the plated cells were chilled on ice, scraped from the plates, and washed twice with chilled buffer $(142 \mathrm{mM}$ $\mathrm{NaCl}, 6.7 \mathrm{mM} \mathrm{KCl}, 10 \mathrm{mM}$ HEPES, pH 7.4). Next the washed cell pellets were solubilized for $30 \mathrm{~min}$ at $4^{\circ}$ in the Triton X-100 extraction buffer. After solubilization, the cell extracts were centrifuged at $10,000 \mathrm{~g}$ for $15 \mathrm{~min}$ at $4^{\circ}$, and the receptor-containing supernatant was subjected to immunoprecipitation using anti-ASGP-R antibody and Protein A-Sepharose as previously described.

Normalization of total radiolabel incorporation in the control and ethanol cell populations was determined through recovery of trichloroacetic acid-precipitable radioactivity after tritiated leucine labeling of the cells. Cultures of control and ethanol cells used in the orthophosphate labeling experiment were incubated overnight at $37^{\circ}$ with $2 \mathrm{mM} \mathrm{L}-\left[4,5-{ }^{3} \mathrm{H}\right]$ leucine (Amersham, $74 \mathrm{Ci} / \mathrm{mmol}$ ) in leucine-free Dulbecco's MEM containing $1 \mathrm{nmol} / \mathrm{L}$ of insulin and $10 \mathrm{nmol} / \mathrm{L}$ each of streptomycin and penicillin. The cells were removed from the plates, washed, and solubilized under the same conditions as the phosphatelabeled cells. A 100- $\mu \mathrm{L}$ sample of the detergent-solubilized protein was removed and placed into $1 \mathrm{~mL}$ of $1 \%$ phosphotungstic acid, $10 \%$ trichloroacetic acid for $30 \mathrm{~min}$ at $4^{\circ}$. The acid precipitates were washed three times with ice-cold $10 \%$ trichloroacetic acid, and the radioactivity in the precipitated pellet was determined after solubilization in 1 $\mathrm{mL}$ of $0.1 \mathrm{~N} \mathrm{NaOH}$.

\section{Other Assays and Statistical Analysis}

DNA concentration was determined by the method of Labarca and Paigen [16]. Statistical analyses were performed by paired Student's $t$-tests. A probability value $\leq$ 0.05 was considered significant.

\section{RESULTS}

In the current study, we examined the possible mechanism(s) responsible for our previously reported alterations in ASGP-R activity, content, and recycling over a time course of ethanol administration by measuring the posttranslational modification of the ASGP-R due to tyrosine phosphorylation. We first examined the phosphorylation status of the ASGP-R in the control and ethanol-fed animals through the sensitive western blot determination of tyrosine-phosphorylated protein present in the receptor. Modification of the ASGP-R due to tyrosine phosphorylation after early (1-2 weeks) and chronic (5-7 weeks) ethanol administration was detected in immunoprecipitated protein using anti-phosphotyrosine antibody conjugated to horseradish peroxidase (Fig. 1A). After normalization to the amount of receptor present on the blot through anti-ASGP-R antibody followed by ${ }^{125}$ I-labeled Protein A detection of the same blots (Fig. 1B), the steady-state level of phosphotyrosine protein present in the ASGP-R was determined. Overall, the amount of phosphotyrosine protein present in RHL-1 in cells obtained from 8-14 animals was increased by $25 \pm 8 \%(P<0.02)$ after 1 week of ethanol administration and $56 \pm 11 \%(P<0.02)$ after $5-7$ weeks in the ethanol cells as compared with the controls. The increase in the phosphorylation state of the receptor was found to be higher in the chronically treated animals when compared with the increase observed after the shorter period of treatment of 1-2 weeks.

To further examine this change in tyrosine phosphorylation of the ASGP-R following ethanol administration, we utilized a permeabilized cell assay system described by Haynes et al. [12] to monitor the biosynthetic phosphate 


\section{A. anti-PY}

\section{B. anti-ASGP-R}

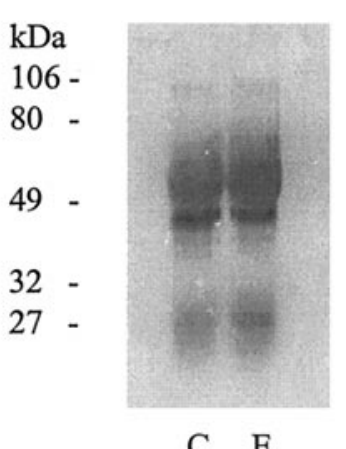

C E

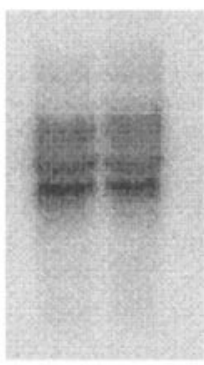

C E

\section{1-2 WEEKS}

\section{WEEKS}
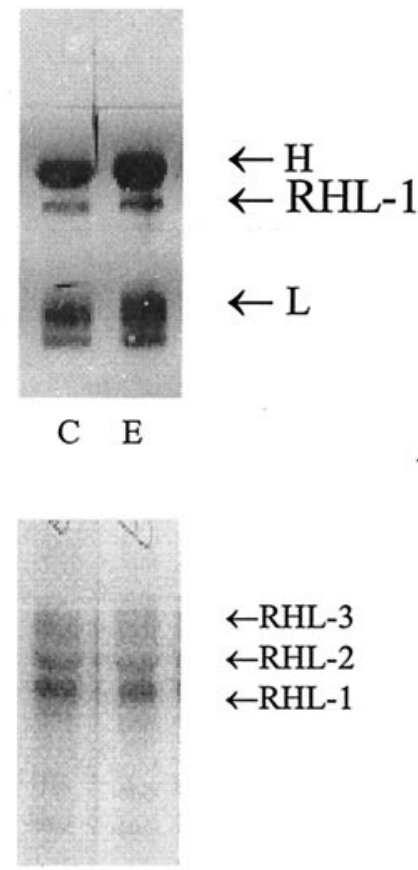

C E
FIG. 1. Steady-state analysis of phosphotyrosine levels in RHL-1 following ethanol administration. ASGP-R was immunoprecipitated from hepatocytes obtained from rats fed either control $(C)$ or ethanol (E) diet over a time course of administration. The ASGP-R protein was separated by SDS-PAGE and transferred to nitrocellulose membranes as described in Materials and Methods. (A) Immunocomplexes from a representative pair of animals were analyzed by western blotting with monoclonal antiphosphotyrosine conjugated with horseradish peroxidase. The molecular mass markers $(\mathrm{kDa})$ are shown on the left, with the positions of RHL-1 and the heavy $(\mathrm{H})$ and light (L) chains of the immunoprecipitating rabbit antiASGP-R antibody noted on the right. (B) Detection of ASGP-R protein present on the blot determined by re-probing of the nitrocellulose with polyclonal rabbit anti-ASGP-R followed by ${ }^{125} \mathrm{I}-\mathrm{la}$ beled Protein A. labeling of the receptor. This in vitro cell assay detects $\left[\gamma-{ }^{32} \mathrm{P}\right]$ ATP labeling of ASGP-R, in which the only phosphorylation event that occurs is the phosphorylation of the tyrosine residue of the major subunit (RHL-1) of the receptor [12]. The first step in analyzing the phosphorylation of ASGP-R under the in vitro conditions was to determine whether we could detect phosphate labeling of the receptor in our isolated hepatocytes obtained from the control and ethanol-fed rats. In these experiments, permeabilized hepatocytes obtained from the pair-fed animals were labeled for $30 \mathrm{~min}$ at $4^{\circ}$ with $\left[\gamma^{32} \mathrm{P}\right] \mathrm{ATP}$, and the ASGP-R was immunoprecipitated, subjected to SDSPAGE, and transferred to nitrocellulose blots. The results of these experiments, shown in Fig. 2, reveal that one band of radioactivity, which was at the appropriate placement for RHL-1, was recovered in ASGP-R extracted from both control and ethanol cells (Fig. 2A). These data indicated that the pattern of ${ }^{32} \mathrm{P}$-labeled proteins was unchanged between cells isolated from control and ethanol-fed animals, as radiolabeling of the major band (RHL-1) was recovered in both cell types. To verify that the entire ASGP-R and not just the major subunit, which was detected by the ${ }^{32} \mathrm{P}$ label, was present on the blot, western analysis using polyclonal anti-ASGP-R antibody followed by iodinated Protein A was performed. The results shown in Fig. 2B demonstrate that the protein extract from the permeabilized cells contained all three subunits of ASGP-R (RHL-1, RHL-2, and RHL-3) identified by SDS-PAGE at 42,49 , and $54 \mathrm{kDa}$, respectively, in both the control and

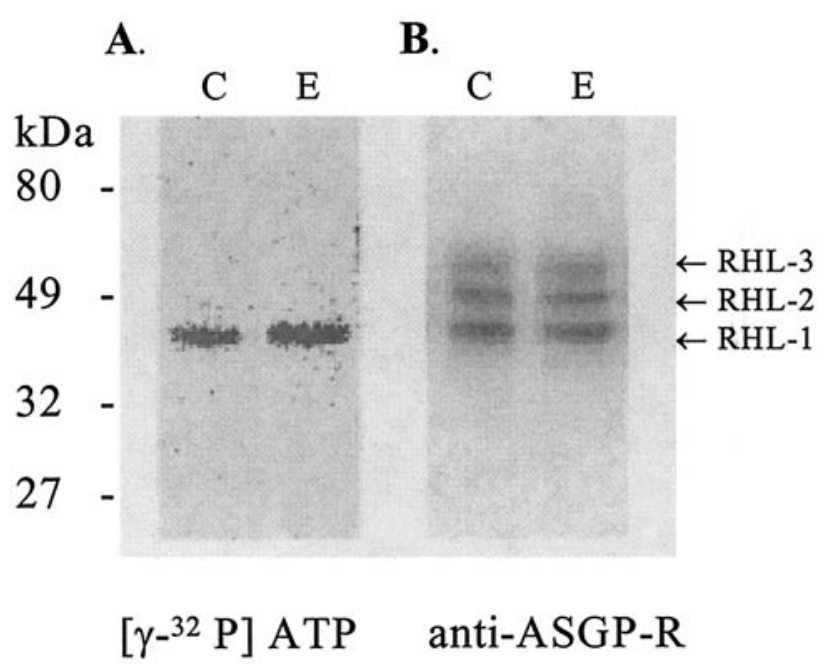

FIG. 2. Determination of in vitro phosphate radiolabeled ASGP-R after ethanol administration. Hepatocytes were obtained from control and ethanol pair-fed rats after 1-2 weeks of ethanol administration. After treatment with digitonin, the cells were incubated for $30 \mathrm{~min}$ at $4^{\circ}$ with phosphorylation buffer containing $500 \mu \mathrm{Ci} / \mathrm{mL}$ of $\left[\gamma-{ }^{32} \mathrm{P}\right] \mathrm{ATP}$. After termination of the reaction and solubilization of the washed cell pellets, the ASGP-R was immunoprecipitated with anti-ASGP-R, separated by SDS-PAGE, and transferred to nitrocellulose as described under Materials and Methods. Panel A illustrates the identification of ${ }^{32}$ P-labeled RHL-1 by PhosphorImager analysis in cells obtained from control (C) and ethanol-treated (E) animals. Panel B shows the determination of ASGP-R protein present on the same blot through western blot analysis with anti-ASGP-R antibody followed by ${ }^{125}$ I-labeled Protein A detection. 
A.

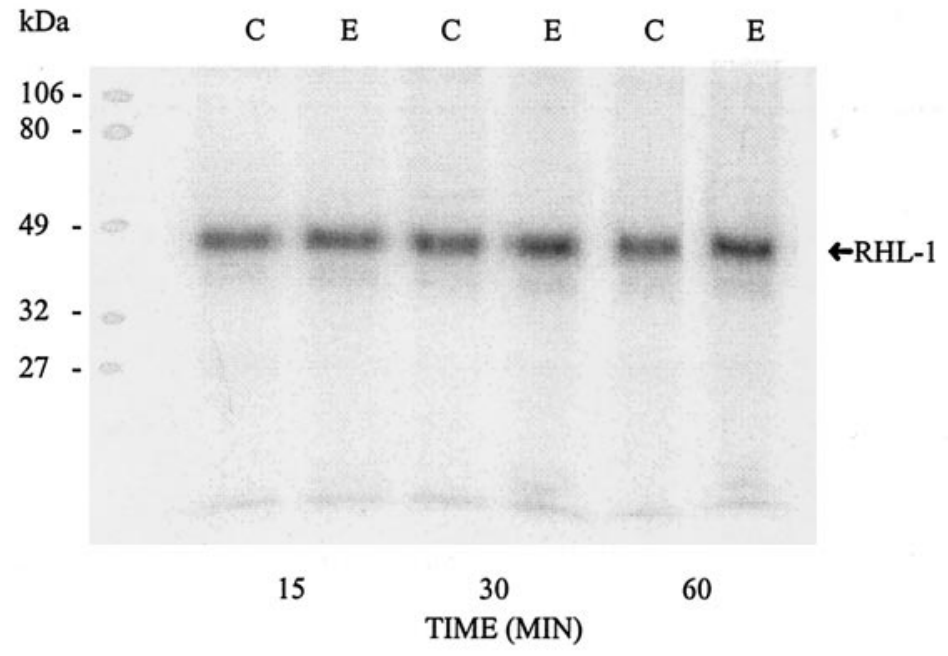

B.

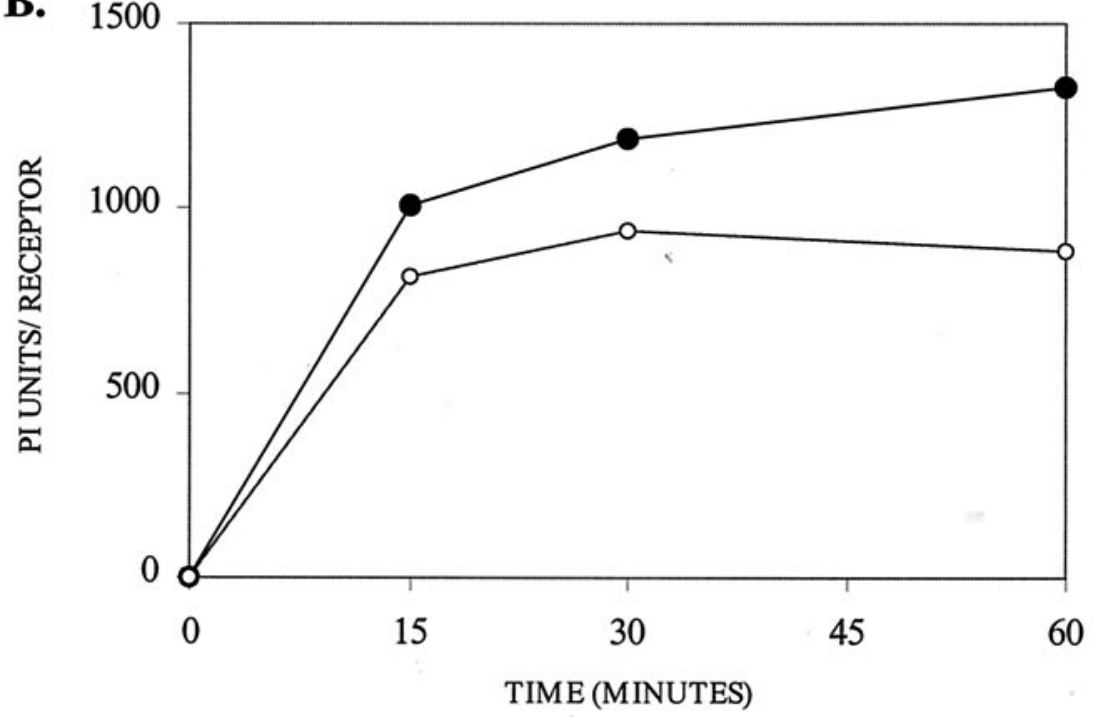

FIG. 3. Effect of ethanol feeding for 1-2 weeks on the phosphorylation of RHL- 1 at $4^{\circ}$. Hepatocytes were isolated from animals treated with liquid diets containing ethanol as $36 \%$ of calories or an isocaloric control diet for 1-2 weeks. Permeabilized rat hepatocytes (10 million) were incubated in $\left[{ }^{32} \mathrm{P}\right] \mathrm{ATP}$ containing phosphorylation buffer, and, at the indicated times, the reaction was stopped and the cells were washed and solubilized as described in Materials and Methods. The ASGP-R was purified from the cell extracts by immunoprecipitation with a $1: 100$ dilution of polyclonal anti-ASGP-R antibody followed by capture on $75 \mu \mathrm{L}$ of packed Protein A-Sepharose beads. Once eluted from the beads, the ASGP-R was subjected to SDS-PAGE and electroblotted onto nitrocellulose. Panel A: radiolabeled ASGP-R obtained from control (C) and ethanol-treated (E) animals as detected by PhosphorImager analysis. The position of molecular mass standards is indicated on the left. Panel B: recovery of radiolabeled phosphate in RHL-1 in control $(\bigcirc)$ and ethanol-treated (O) hepatocytes over the time course of phosphorylation. Data in panel B, expressed as PhosphorImager (PI) units per ASGP-R, show one representative pair of animals from a total of $6-8$ pairs of animals. ethanol cells. Therefore, the data presented in Fig. 2 (representing phosphorus radiolabeling and western blot analysis) confirmed that in our assay system, we could detect tyrosine phosphorylation of the RHL-1 subunit of ASGP-R at $4^{\circ}$ using the permeabilized cell assay system. Additional preliminary experiments using the in vitro permeable cell assay system indicated that the addition of 20 $\mathrm{mM}$ EDTA as well as $1.0 \mathrm{mM}$ tyrphostin 51 to the phosphorylation medium inhibited the radiolabeling of RHL-1. The incorporation of $\left[\gamma-{ }^{32} \mathrm{P}\right]$ ATP was inhibited by 95\% in both control and ethanol cells after the addition of the cation chelator, and decreased by an average of $86 \%$ after the addition of the tyrosine kinase inhibitor (data not shown). This dependence on the presence of divalent cations and tyrosine kinase activity has also been shown by others $[12,14,17]$. Results of these experiments show that the phosphorylation of RHL-1 in both control and ethanol cells requires the presence of divalent cations, which are essential for protein kinase activity, and that this process requires an active tyrosine kinase in both cell types.

In the initial control experiments as indicated in Fig. 2, we observed an apparent increase in the phosphorylation of RHL-1 in the ethanol cells as compared with the controls (panel A, Fig. 2). To further characterize the phosphate labeling in the ethanol-treated cells, we measured the tyrosine phosphorylation of ASGP-R in the isolated cells over a time course of radiolabeling. Figure 3 illustrates a typical PhosphorImager analysis of ${ }^{32} \mathrm{P}$-labeled ASGP-R in hepatocytes from animals fed ethanol for the early 1-2 week feeding period. The data indicate that the phosphorylation of RHL-1 was increased in the ethanol cells (25-40\%) as compared with controls over a time course of labeling up to $60 \mathrm{~min}$. When the tyrosine phosphorylation of ASGP-R was measured in cells from animals that were chronically fed ethanol for 5-7 weeks, hyperphosphorylation of the receptor was again observed over $60 \mathrm{~min}$ of 
A.

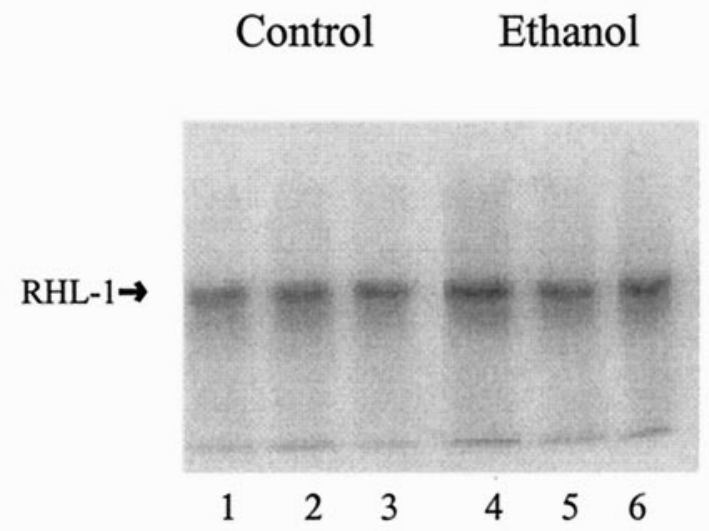

B.

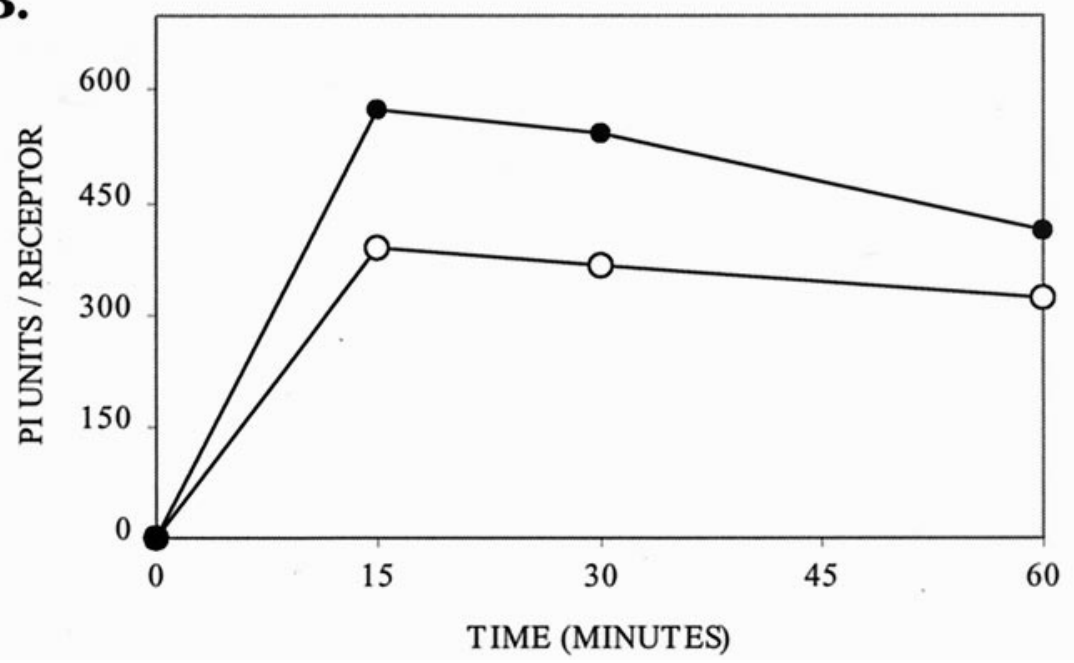

FIG. 4. Effect of chronic (5-7 weeks) ethanol treatment on the phosphorylation of RHL-1 in permeabilized rat hepatocytes at $4^{\circ}$. Hepatocytes were obtained from control and ethanol pair-fed rats after 5-7 weeks of administration. The recovery of phosphate radiolabeled RHL-1 after a time course of phosphorylation was conducted as described in the legend of Fig. 3. Panel A: PhosphorImager analysis of ${ }^{32} \mathrm{P}$-labeled RHL-1 in control and ethanol cells recovered after $15 \mathrm{~min}$ (lanes 1 and 4), $30 \mathrm{~min}$ (lanes 2 and 5) and $60 \mathrm{~min}$ (lanes 3 and 6) of incubation. Panel B: time course of phosphorylation of RHL-1 in 5-week-treated hepatocytes (control, $\bigcirc$; ethanol, $\bigcirc$ ) expressed as PhosphorImager units (PI) per ASGP-R. Data in panel B show one representative pair of animals from a total of $6-8$ pairs of animals. labeling (Fig. 4). Again, the data presented as PhosphorImager units per receptor show significant increases in the amount of radiolabeled RHL-1 that was recovered after immunoprecipitation in the ethanol cells as compared with the controls. The data are presented as PhosphorImager units per content of receptor since after long-term ethanol treatment, the amount of the ASGP-R is decreased as previously shown by anti-ASGP-R antibody binding.

Since the phosphorylation of RHL-1 was complete by 30 $\min \left(\mathrm{T}_{1 / 2} \approx 5 \mathrm{~min}\right)$ of incubation at $4^{\circ}$ with $\left[^{32} \mathrm{P}\right] \mathrm{ATP}$ for both ethanol feeding periods, we chose this time period to collectively measure the labeling of tyrosine-5 of RHL-1. When results of $8-10$ pairs of animals were analyzed, the amount of radioactivity recovered in the RHL-1 subunit in the ethanol-fed animals was found to be increased significantly by $82 \pm 32$ and $80 \pm 21 \%$ in the 1 - and 5 -week-fed rats, respectively. These data suggest that the major subunit of the ASGP-R is hyperphosphorylated in hepatocytes from ethanol-fed rats in this in vitro permeabilized cell assay.

To determine if the ability of the ASGP-R to become dephosphorylated was affected by ethanol, we labeled the permeabilized cells at $4^{\circ}$ as before with $\left[{ }^{32} \mathrm{P}\right] \mathrm{ATP}$ and then incubated the cells at $37^{\circ}$ for up to $60 \mathrm{~min}$. The dephosphorylation of ASGP-R was essentially complete by $60 \mathrm{~min}$ $\left(\mathrm{T}_{1 / 2} \approx 10 \mathrm{~min}\right)$ and followed a similar pattern for both the control and the ethanol-fed rats over the time course of diet administration (Fig. 5). Thus, the phosphatase activity required to dephosphorylate the ASGP-R appeared to be unaffected by ethanol administration over both a short- and a long-term course of feeding. These results suggest that the interaction and/or stimulation of tyrosine kinases, rather than the inhibition of protein phosphatases, may play a more important role in the observed hyperphosphorylation of the ASGP-R.

In addition to the in vitro labeling of phosphotyrosine, we also performed metabolic incorporation studies in the control and ethanol-treated cells. For these studies, isolated hepatocytes obtained from animals treated over the time course of administration were radiolabeled biosynthetically with $\left[{ }^{32} \mathrm{P}\right]$ orthophosphate overnight at $37^{\circ}$. PhosphorImager detection of the ${ }^{32} \mathrm{P}$ label after immunoprecipitation of ASGP-R indicated that all three subunits of the receptor 


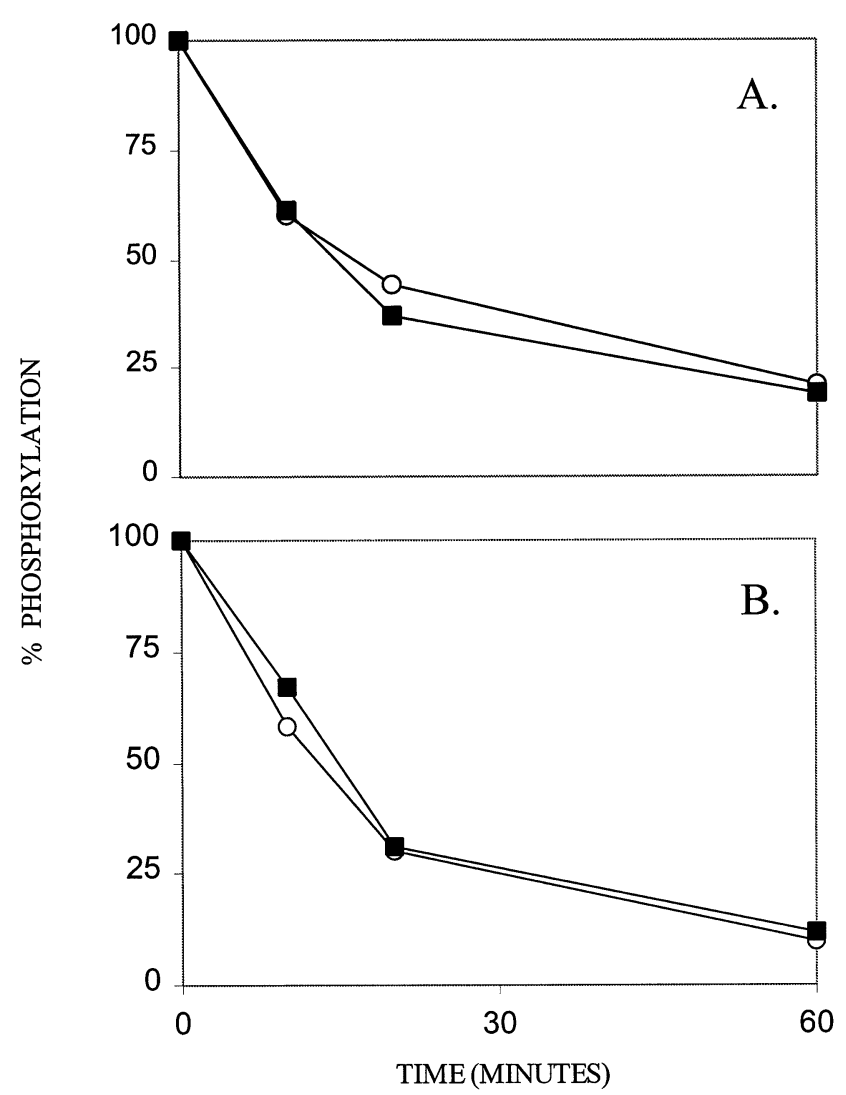

FIG. 5. Dephosphorylation of RHL-1 after both short- and long-term periods of ethanol administration. Hepatocytes isolated from animals treated with ethanol for 1-2 (A) and 5-7 weeks (B) were permeabilized, washed, and labeled with 500 $\mu \mathrm{Ci} / \mathrm{mL}$ of $\left[{ }^{32} \mathrm{P}\right] \mathrm{ATP}$ for $30 \mathrm{~min}$ at $4^{\circ}$. At time 0 , the samples were incubated at $37^{\circ}$ for up to $60 \mathrm{~min}$, after which the reaction was terminated and the cells were washed and solubilized as described before. The ASGP-R was recovered by immunoprecipitation as described in the legend of Fig. 2 and quantified by PhosphorImager analysis. Data are presented as the percentage of phosphorylation of the RHL-1 receptor band over the time course for control $(\bigcirc)$ and ethanol-treated $(\square)$ hepatocytes.

incorporated the label (data not shown). The extent of total ${ }^{32} \mathrm{P}$ incorporation into ASGP-R was found to be increased significantly by $54 \pm 29 \%(P<0.03)$ in the chronically (5- to 7-week) ethanol-treated rats when compared with the basal level observed in the control animals. An increase (54\%) in the metabolic labeling of ASGP-R after the early period of ethanol administration also was observed, although due to the variation in the effect of ethanol in this animal population, the increase was not found to be significant.

\section{DISCUSSION}

The liver specific ASGP-R directs the RME of circulating desialylated glycoproteins in hepatocytes. In recent years, tyrosine phosphorylation of the ASGP-R has been implicated in the regulation of receptor activity and endocytosis. Studies have established that the major rat hepatic lectin subunit (RHL-1) of the ASGP-R contains the only cyto- plasmic tyrosine residue available for phosphate labeling, which is located at position 5 in the cytoplasmic tail of the receptor. The phosphorylation of this residue has been shown to be altered by tyrosine kinase $[9,10]$ and phosphatase inhibitors [8], and has been shown to play a role in the process of receptor inactivation [12].

In the present study, we investigated the effects of ethanol on the tyrosine phosphorylation of ASGP-R to determine if the phosphorylation state of the receptor could be involved in the previously observed ethanol-induced alterations in ASGP-R function. The approach of this work was to measure the phosphorylation state of the ASGP-R using a combination of experimental designs from the biosynthetic incorporation of phosphate to the measurement of steady-state phosphotyrosine levels. The results of this study indicate that the ASGP-R in isolated rat hepatocytes obtained after both an early exposure to ethanol of 1-2 weeks and a longer, more chronic feeding period of 5-7 weeks is hyperphosphorylated in response to ethanol treatment. Overall, the observed increase in tyrosine phosphorylation could contribute to the altered function of the ASGP-R that was seen over the time course of ethanol administration.

Specifically, we have found that the steady-state phosphorylation of the tyrosine-5 residue of RHL-1 was increased in the ethanol-fed animals as compared with the basal levels of control animals. Although significantly increased in both the 1-2 and 5-7 week ethanol-fed rats, the level of phosphotyrosine measured in the long-term ethanol-fed animals was twice that observed after the short-term period of administration. These results indicate that over a time course of ethanol administration, there is a differential effect observed on the hyperphosphorylation of the ASGP-R. In addition, the experiments indicate that the tyrosine hyperphosphorylation is present in intact cells that have been isolated from the whole liver and incubated at $37^{\circ}$, a temperature where constitutive endocytosis occurs. To examine the radiolabeling event more clearly, a series of experiments were performed at $4^{\circ}$ using an in vitro labeling technique that only labels tyrosine- 5 of the cytoplasmic tail that is involved in endocytosis. The radiolabeling experiments also revealed an increase in the tyrosine phosphorylation of the receptor. For instance, in vitro radiolabeling of RHL-1 was found to be increased significantly by an average of $80 \%$ in cells obtained from both the 1-2 and 5-7 week periods of alcohol administration. Since in this assay tyrosine phosphorylation is the exclusive radiolabeling event, we did not observe a differential ethanol effect on the tyrosine phosphorylation of RHL-1 between the early and chronic treatment periods due to the maximum radiolabeling potential. The biosynthetic labeling of the ASGP-R with $\left[{ }^{32} \mathrm{P}\right]$ orthophosphate also resulted in hyperphosphorylation of the receptor after the chronic 5- to 7-week period of ethanol treatment. Although labeling with orthophosphate would result in phosphate incorporation into serine, threonine, and tyrosine, the general concept of hyperphosphorylation is supported by these 
results in a more in vivo situation. Our data indicate that the increase in the level of phosphotyrosine of the ASGP-R after early ethanol administration is not as dramatic as that observed after long-term ethanol treatment. Upon more prolonged ethanol feeding of 5-7 weeks, the extent and significance of ethanol-induced hyperphosphorylation of ASGP-R correlate with the adaptive changes that have occurred in the cell in which there is a significant downregulation of the receptor and decreased mRNA content in addition to altered activity.

We suggest that the observed increase in phosphotyrosine protein of the ASGP-R may contribute to alterations in the function of the receptor that are seen after ethanol administration. It is hypothesized that changes in the phosphorylation/dephosphorylation cycle of the receptor may cause defects in the trafficking pathway of the receptor that may inhibit proper internalization and clustering into the coated pits, as well as impairments in the recycling process [13].

While it is also possible that changes in ASGP-R function following ethanol administration could lead to an accumulation of non-recycling receptors that are subsequently phosphorylated following changes in normal receptor trafficking, our hypothesis that the hyperphosphorylation of the ASGP-R that is observed after ethanol treatment precedes changes in trafficking events is supported by several other investigations $[12,18,19]$. We feel that the hyperphosphorylation could contribute to the redistribution and accumulation of receptors after early ethanol treatment and, after long-term ethanol administration, the accumulated receptors could become part of a non-recycling pool of receptors that are likely to be degraded rather than recycled. In support of this hypothesis, several studies have noted that changes in the phosphorylation of ASGP-R could be involved in the regulation of the function and endocytosis of the receptor [12, 18, 19]. For example, initial internalization events may be impaired by hyperphosphorylation. It has been demonstrated from crystal structure analysis that the tyrosine residue of cytoplasmic signal motifs of receptors involved in clathrin-mediated endocytosis will not function properly if phosphorylated, due to the constraints of the hydrophobic binding pocket that is recognized by adaptor proteins [20]. The ASGP-R belongs to the family of receptors that are internalized by the clathrin-dependent vesicles and contains the consensus sequence, which is involved in the formation of the required hydrophobic binding pocket.

Other endocytic events also could be altered by increased phosphorylation of the ASGP-R, as Weigel and colleagues have reported that ASGP-R phosphorylation is a prerequisite for ATP-dependent inactivation of the receptor in permeabilized rat hepatocytes [12]. In another work, Treichel et al. [18] have shown that the exposure of HepG2 cells to the cytokine interleukin-2 causes a reduction in the binding activity of surface ASGP receptors that is accompanied by hyperphosphorylation of the receptor. Also, it has been reported that the addition of phorbol esters causes a 3- to 5-fold increase in the ASGP-R phosphorylation in HepG2 cells [19]. This work led to the suggestion that receptor modification by phosphorylation may involve a stable non-recycling pool of intracellular ASGP receptors. Therefore, to hypothesize that enhanced phosphorylation of the ASGP-R following ethanol administration could result in intracellular sequestration and possible degradation through an inhibitory mechanism of receptor sorting and recycling is consistent with the data presented in this study as well as other published works.

One of the potential mechanisms responsible for the hyperphosphorylation of the ASGP-R could involve an increase of protein tyrosine kinase activity in the ethanolfed animals. Whether or not ethanol and/or its metabolites are involved in the activation of phosphotyrosine kinases is uncertain. However, since the in vitro analysis presented here indicated that dephosphorylation of RHL-1 occurred rapidly and to the same extent in both control and ethanol-treated hepatocytes (Fig. 5), it appears that the activities of membrane-associated protein phosphatases (two of which have been identified previously in rat hepatocytes [21]) are probably unaffected by ethanol administration. Thus, further identification and characterization of kinase activity could provide a better understanding of the effects ethanol exerts on signal transduction events.

In summary, the role of tyrosine phosphorylation of the ASGP-R could involve multiple aspects of RME. The endocytic pathway appears to be regulated by protein phosphorylation at several steps including internalization, receptor recycling, endosome fusion, and transport [13]. Initial internalization events of the ASGP-R could be altered upon increased phosphorylation of the receptor, as the addition of the phosphate group could interfere with the normal signaling process in clathrin-mediated endocytosis. Another event that could be altered by ethanolinduced hyperphosphorylation of the ASGP-R is the ability of the receptor and ligand to dissociate. It has been shown previously that ethanol administration alters the acidic intravesicular $\mathrm{pH}$ of endosomal compartments, resulting in impairments of receptor-ligand dissociation [6]. The phosphorylation of the ASGP-R could contribute to the slow or incomplete separation of ligand and receptor seen after ethanol treatment, as the receptor is inactivated and redistributed after early ethanol administration. And finally, after more prolonged periods of ethanol treatment, enhancement of the ASGP-R phosphorylation state may be involved in the accumulation of the receptor in nonrecycling endosomal pools, which correlates with the altered receptor trafficking and down-regulation of the receptor that were observed after chronic ethanol administration.

This research was supported by Grants AA04961 and AA07846 from the National Institute on Alcohol Abuse and Alcoholism and by the Department of Veterans Affairs. 


\section{References}

1. Tuma DJ and Sorrell MF, Effects of ethanol on protein trafficking in the liver. Semin Liver Dis 8: 69-80, 1988.

2. Tuma DJ and Sorrell MF, Effects of ethanol on the secretion of glycoproteins by rat liver slices. Gastroenterology 80: 273278, 1981.

3. Casey CA, Kragskow SL, Sorrell MF and Tuma DJ, Chronic ethanol administration impairs the binding and endocytosis of asialo-orosomucoid in isolated rat hepatocytes. J Biol Chem 262: 2704-2710, 1987.

4. Schwartz AL, Trafficking of asialoglycoproteins and the asialoglycoprotein receptor. In: Liver Diseases (Eds. Wu G and Wu C), pp. 3-9. Marcel Dekker, New York, 1991.

5. Casey CA, Kragskow SL, Sorrell MF and Tuma DJ, Ethanolinduced impairments in receptor-mediated endocytosis of asialoorosomucoid in isolated rat hepatocytes: Time course of impairments and recovery after ethanol withdrawal. Alcohol Clin Exp Res 13: 258-263, 1989.

6. Casey CA, Wiegert RL and Tuma DJ, Chronic ethanol administration impairs ATP-dependent acidification of endosomes in rat liver. Biochem Biophys Res Commun 195: 11271133, 1993.

7. Tworek BL, Tuma DJ and Casey CA, Decreased binding of asialoglycoproteins to hepatocytes from ethanol-fed rats: Consequence of both impaired synthesis and inactivation of the asialoglycoprotein receptor. J Biol Chem 271: 2531-2538, 1996.

8. Holen I, Gordon PB, Stromhaug PE, Berg TO, Fengsrud M, Brech A, Roos N, Berg $\mathrm{T}$ and Seglen PO, Inhibition of asialoglycoprotein endocytosis and degradation in rat hepatocytes by protein phosphatase inhibitors. Biochem J 311: 317-326, 1995.

9. Fallon RJ and Danaher M, The effect of staurosporine, a protein kinase inhibitor, on asialoglycoprotein receptor endocytosis. Exp Cell Res 203: 420-426, 1992.

10. Fallon RJ, Danaher M, Saylors RL and Saxena A, Defective asialoglycoprotein receptor endocytosis mediated by tyrosine kinase inhibitors. J Biol Chem 269: 11011-11017, 1994.
11. Fallon RJ, Danaher M and Saxena A, The asialoglycoprotein receptor is associated with a tyrosine kinase in HepG2 cells. J Biol Chem 269: 26626-26629, 1994.

12. Haynes PA, Medh JD and Weigel PH, Inhibition of tyrosine phosphorylation in the rat hepatic lectin 1 subunit of the rat asialoglycoprotein receptor prevents ATP-dependent receptor inactivation in permeabilized hepatocytes. J Biol Chem 269: 33152-33158, 1994.

13. Stoorvogel W, Schwartz AL, Strous GJ and Fallon RJ, A pool of intracellular phosphorylated asialoglycoprotein receptors which is not involved in endocytosis. J Biol Chem 266: 5438-5444, 1991.

14. Haynes PA, Oka JA and Weigel PH, The rat hepatic lectin 1 subunit of the rat asialoglycoprotein receptor is a phosphoprotein and contains phosphotyrosine. J Biol Chem 269: 33146-33151, 1994.

15. Lieber $\mathrm{C}$ and DeCarli M, The feeding of alcohol in liquid diets: Two decades of application and 1982 update. Alcohol Clin Exp Res 6: 523-531, 1982.

16. Labarca $\mathrm{C}$ and Paigen $\mathrm{K}, \mathrm{A}$ simple, rapid, and sensitive DNA assay procedure. Anal Biochem 102: 344-352, 1980.

17. Fallon RJ, Tyrosine phosphorylation of the asialoglycoprotein receptor. J Biol Chem 265: 3401-3406, 1990.

18. Treichel U, Paietta E, Poralla T, Meyer K, Büschenfelde Z and Stockert RJ, Effects of cytokines on synthesis and function of the hepatic asialoglycoprotein receptor. J Cell Physiol 158: 527-534, 1994.

19. Fallon RJ and Schwartz AL, Asialoglycoprotein receptor phosphorylation and receptor-mediated endocytosis in hepatoma cells. J Biol Chem 263: 13159-13166, 1988.

20. Owen DJ and Evans PR, A structural explanation for the recognition of tyrosine-based endocytotic signals. Science 282: 1327-1332, 1998.

21. Gruppuso PA, Boylan JM, Smiley BL, Fallon RJ and Brautigan $\mathrm{DL}$, Hepatic protein tyrosine phosphatases in the rat. Biochem J 274: 361-367, 1991. 